\title{
Caesarean Delivery in South-Western Iran: Trends and Determinants in a Community-Based Survey
}

\author{
Najmeh Maharlouei ${ }^{a} \quad$ Mansoureh Moalaee $^{b} \quad$ Saeed Ajdari $^{b} \quad$ Maasoumeh Zarei $^{b}$ \\ Kamran B. Lankarania \\ ${ }^{a}$ Health Policy Research Center, School of Medicine, Shiraz University of Medical Sciences, and ${ }^{b}$ Clinical Affairs, \\ Shiraz University of Medical Sciences, Shiraz, Iran
}

\section{Key Words}

Caesarean delivery $\cdot$ Iran $\cdot$ Trend

\begin{abstract}
Objective: To assess trends in caesarean delivery and its associated factors in south-western Iran. Subjects and Methods: This cross-sectional study was conducted from January 2007 to January 2010 in Fars province, Iran. All deliveries recorded in public and private hospitals were included. The Mann-Whitney $U$ test, $\chi^{2}$ test and multivariate logistic regression models were used for analysis of data. A $p$ value less than 0.05 was considered significant. Results: The rate of caesarean section for the whole sample of 139,159 increased from $51.6 \%$ in 2007 to $53.3 \%$ in 2009 , which was statistically and clinically significant. The rate of caesarean delivery was significantly higher in primiparous compared to multiparous mothers. The rate increased steadily with the mother's age. The most prevalent recorded reason for caesarean delivery was maternal request. Logistic regression analysis showed that maternal age, previous abortions, underlying maternal disease, gestational age and number of living children were key contributing factors to the choice of mode of delivery. Conclusion: This study showed an increasing rate of caesarean delivery which should draw the attention of policymakers to factors associated with this mode of delivery.
\end{abstract}

Copyright ๑ 2012 S. Karger AG, Basel

\section{KARGER}

E-Mail karger@karger.ch www.karger.com/mpp

\section{(c) 2012 S. Karger AG, Basel} 1011-7571/13/0222-0184\$38.00/0

Karger

0 pen access

This is an Open Access article licensed under the terms of the Creative Commons Attribution- NonCommercial-NoDerivs 3.0 License (www.karger.com/OA-license), applicable to the online version of the article only. Distribution for non-commercial purposes only.

\section{Introduction}

Caesarean delivery has several medical and non-medical indications $[1,2]$. Medical indications are divided into two subcategories: definite medical indications such as foetal distress syndrome, breech presentation or placenta previa, and vague medical indications such as previous caesarean delivery, failure to progress during labour and presumed foetal compromise $[1,2]$. One of the main non-medical reasons for caesarean delivery is maternal request $[1,2]$.

The rate of caesarean delivery is increasing worldwide [2]. For example, in the United Kingdom in 1953, only $2 \%$ of all recorded deliveries were caesarean deliveries, but the rate reached $18 \%$ in 1997 and 21\% in 2001 [2]. In Iran, a developing country, the rate rose from $35 \%$ in 2000 [3] to $47 \%$ in 2005 [4]. In addition, surveys report higher percentages of caesarean deliveries in private hospitals compared to governmental facilities $[5,6]$.

Caesarean delivery, including elective caesarean delivery, is a risky procedure for both the mother and child [2, 7]. However, maternal requests for elective caesarean delivery are becoming the leading cause for this choice, which now accounts for between 0.3 and $14 \%$ of all caesarean deliveries worldwide [8]. According to the World Health Organization, the maximum acceptable rate of caesarean delivery is $15 \%$ [9]. However, this goal may not

Kamran B. Lankarani, MD

Health Policy Research Center

Building No. 2, 8th Floor, School of Medicine, Zand Avenue

PO Box 71345-1877, Shiraz (Iran)

Tel. +98 711230 9615, E-Mail lankaran@sums.ac.ir 
Table 1. Characteristics of primiparous versus multiparous mothers

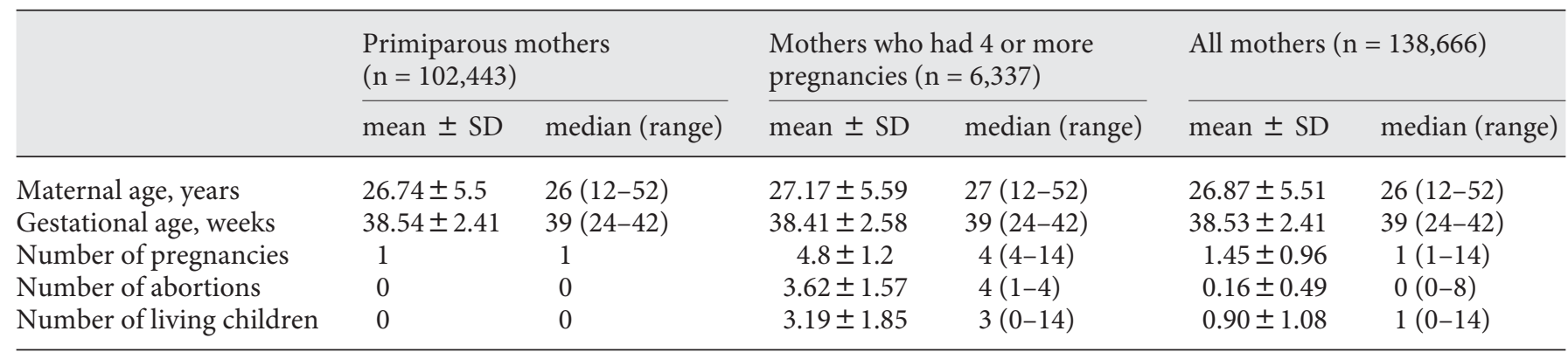

have been achieved in countries like Iran, where the rate of caesarean delivery was remarkably high [3]. To our knowledge, since 2005 no community-based surveys have been published. Therefore, in this study we aimed to measure the rate of caesarean delivery in a community-based survey in Fars province, south-western Iran. We also tried to identify factors associated with this mode of delivery.

\section{Subjects and Methods}

\section{Design and Setting}

A descriptive-analytical cross-sectional study was conducted in Fars province, Iran. The total population and the number of childbearing women, obtained from the report of the Iranian Census of Population and Housing 2006, were 4,500,000 and $1,334,046$, respectively. The total number of deliveries from January 1,2007 to December 31, 2009 in all public and private hospitals and delivery facilities in the province was the study denominator. Other deliveries performed outside these hospitals and facilities (e.g. home deliveries) were excluded. Therefore, a total of 139,266 deliveries were recorded in Fars province from January 1, 2007 to December 31, 2009, and the data for 138,666 individuals were usable.

\section{Data Collection}

Detailed information was obtained for each delivery. At each hospital and delivery facility at least one trained nurse extracted the information from the prenatal care cards and surgical reports in the mother's hospital record. The nurse then recorded the information on a standardized computerized form and sent it daily to the deputy of clinical affairs of Shiraz University of Medical Sciences and the Statistics and Registration Administration Office. After the survey was approved by the Shiraz University of Medical Sciences, to ensure appropriate access to the clinical information, a midwife or a gynaecologist explained the purpose of the study to each woman at the time of delivery and asked her to provide her consent for data about her delivery to be included in the study.

Each computerized form contained demographic and obstetric information. The demographic data included the woman's first and last name, hospital file code, city, age and underlying diseases (hypertension, diabetes mellitus, ischaemic heart disease and asthma). The obstetric information consisted of past obstetric history including the number of pregnancies, number of living children, abortions, and present obstetric history, i.e. delivery date and gestational age, and reasons (if any) for choosing caesarean instead of vaginal delivery.

\section{Statistical Analysis}

The data were analysed with SPSS version 15 software. The Mann-Whitney $U$ test was used to compare age, gestational age and number of pregnancies and abortions between the women who had a normal vaginal delivery and those who had a caesarean delivery. The $\chi^{2}$ test was used to identify differences in the rates of caesarean delivery between public and private hospitals as well as between the years 2007 and 2009. Outcome-specific multivariate logistic regression models with the backward and forward stepwise method were used to identify the main reasons why the women chose caesarean delivery. Differences with a p value $<0.05$ were considered statistically significant. The data are reported as the mean \pm standard deviation.

\section{Results}

The overall mean rate of caesarean delivery was $52.2 \%$. The mean age of the women was $26.87 \pm 5.51$ years (range 12-52) at the time of delivery. The mean gestational age was $38.53 \pm 2.41$ weeks (range $24-42$ ). Demographic information regarding the number of pregnancies, living children and abortions are shown in table 1.

The rate of caesarean delivery increased significantly $(\mathrm{p}<0.001)$ in the 3 years of this study from $51.6 \%$ in 2007 and 2008 to $53.3 \%$ in 2009. Most of the mothers $(102,443$; $73.8 \%$ ) were primiparous. In this group, more than half of the women $(54,659 ; 53.4 \%)$ gave birth by caesarean delivery, and maternal request was the most frequently recorded reason $(38.4 \%)$. Of the 6,337 mothers who had been pregnant 4 times or more, $2,853(45 \%)$ had a caesarean de- 
Table 2. Characteristics of mothers who had a normal vaginal delivery versus a caesarean delivery

\begin{tabular}{|c|c|c|c|}
\hline & $\begin{array}{l}\text { Normal vaginal } \\
\text { delivery } \\
(\mathrm{n}=66,296)\end{array}$ & $\begin{array}{l}\text { Caesarean } \\
\text { delivery } \\
(\mathrm{n}=72,370)\end{array}$ & $\begin{array}{l}\mathrm{p} \\
\text { value }\end{array}$ \\
\hline \multicolumn{4}{|l|}{ Age group } \\
\hline$<19$ years & $3,098(57.6 \%)$ & $2,279(42.4 \%)$ & \multirow[t]{3}{*}{$<0.001$} \\
\hline 19-34 years & $56,727(47.5 \%)$ & $62,666(52.5 \%)$ & \\
\hline$>34$ years & $6,471(46.6 \%)$ & $7,425(53.4 \%)$ & \\
\hline \multicolumn{4}{|l|}{ Gestational age } \\
\hline$<28$ weeks & $1,120(64 \%)$ & $630(36 \%)$ & \multirow[t]{4}{*}{$<0.001$} \\
\hline 28-36 weeks & $4,269(41.5 \%)$ & $6,006(58.5 \%)$ & \\
\hline $37-40$ weeks & $54,738(46.8 \%)$ & $62,149(53.2 \%)$ & \\
\hline$>40$ weeks & $6,169(63.2 \%)$ & $3,585(36.8 \%)$ & \\
\hline \multicolumn{4}{|c|}{ Number of pregnancies } \\
\hline 1 & $47,784(46.6 \%)$ & $54,659(53.4 \%)$ & \multirow[t]{4}{*}{$<0.001$} \\
\hline 2 & $10,576(49.7 \%)$ & $10,713(50.3 \%)$ & \\
\hline 3 & $4,281(51.8 \%)$ & $3,991(48.2 \%)$ & \\
\hline 4 or more & $3,484(55 \%)$ & $2,853(45 \%)$ & \\
\hline \multicolumn{4}{|c|}{ Number of living children } \\
\hline 0 & $23,614(44.9 \%)$ & $28,949(55.1 \%)$ & \multirow[t]{5}{*}{$<0.001$} \\
\hline 1 & $17,956(43.7 \%)$ & $23,112(56.3 \%)$ & \\
\hline 2 & $8,568(50.6 \%)$ & $8,374(49.4 \%)$ & \\
\hline 3 & $3,215(56.2 \%)$ & $2,508(43.8 \%)$ & \\
\hline 4 or more & $1,973(61.5 \%)$ & $1,235(38.5 \%)$ & \\
\hline \multicolumn{4}{|c|}{ Number of abortions } \\
\hline 0 & $51,943(45.7 \%)$ & $61,632(51.5 \%)$ & \multirow[t]{3}{*}{$<0.001$} \\
\hline $1-2$ & $10,641(56.1 \%)$ & $8,343(57.3 \%)$ & \\
\hline 3 or more & $3,541(61.2 \%)$ & $2,241(58.9 \%)$ & \\
\hline
\end{tabular}

$\mathrm{p}<0.05$ according to the $\chi^{2}$ test was considered significant. livery, and the reason recorded most frequently was previous caesarean delivery. This reflected an increasing trend towards normal vaginal delivery among the women who had a higher number of pregnancies. However, this is secondary to many factors such as maternal age and maternal underlying diseases. The comparison of primiparous and multiparous mothers is summarized in table 1 . There was a tendency towards normal vaginal delivery in the younger age groups (15-18 years; $\mathrm{p}<0.001$; 95\% CI: 1.43-1.44); however, as the mother's age increased the rate of caesarean delivery also increased significantly $(\mathrm{p}<0.001)$. For gestational ages of 27 weeks or less and 41 weeks or more, the rate of normal vaginal delivery was higher than caesarean delivery (64 vs. $63.2 \%$, respectively). In contrast, between the gestational ages of 28 and 40 weeks, the rate of caesarean delivery was higher $(52.4 \%)$ than the rate of normal vaginal delivery. About one quarter of all deliveries $(37,078 ; 27.6 \%)$ were performed in the 39th week of pregnancy, and of these 21,825 (58.9\%) were caesarean de- liveries. The most prevalent reason recorded for caesarean delivery in this group was maternal request (29.1\%).

The higher the number of abortions, the higher was the rate of caesarean delivery. In mothers with no living children or 1 living child, the rate of caesarean delivery was significantly $(\mathrm{p}<0.001)$ higher than normal vaginal delivery (55.1 vs. $56.3 \%$, respectively). In mothers with 2 or more living children, however, the rate of normal vaginal delivery was higher.

The following were the recorded reasons for caesarean delivery: elective caesarean delivery (36.3\%), previous caesarean delivery (28.1\%), foetal complications (19.1\%) and maternal complications (16.4\%). The frequencies of these categories differed significantly $(\mathrm{p}<0.001)$.

A small proportion of mothers $(2,182$ out of 138,666 ; $1.57 \%)$ reported at least one underlying disease. Of 136,484 mothers who had no underlying disease, 71,290 (52.2\%) underwent caesarean delivery, whereas this rate was $49.5 \%$ in mothers with underlying diseases. It should be noted that maternal underlying disease was found in 1,080 out of 72,370 caesarean deliveries (1.5\%), compared to 1,102 normal vaginal deliveries $(1.7 \%)$.

The comparison between maternal age, gestational age, number of pregnancies, number of living children and number of abortions in mothers who gave birth by normal vaginal delivery and those who had caesarean delivery is listed in table 2 .

Logistic regression analysis showed that maternal age, number of living children, number of previous abortions, maternal underlying disease and gestational age were found to be associated with the choice of mode of delivery (table 3).

\section{Discussion}

In this study, the rate of caesarean delivery in Fars province was $52.2 \%$, which is substantially higher than the World Health Organization's recommended rate of $15 \%$ [9]. Furthermore, the rate of caesarean delivery was significantly higher than the $26.3 \%$ estimates for Southeast Asian countries [10] and also for Middle East countries [11]. However our findings are similar to the previous study conducted in Fars province (66.4\%) [12].

Although there was an increase in the rate of caesarean delivery (3.3\%) between 2008 and 2009, a similar increase has been observed in most countries, both developed and developing [11-18]. The slope of the increase in Fars province was not as steep as in some countries such as China, where the rise in caesarean delivery rates ranged from 36.3 
Table 3. Associations between maternal factors and mode of delivery using logistic regression analysis

\begin{tabular}{|c|c|c|c|}
\hline Variables & Significance & $\begin{array}{l}\text { Odds ratio } \\
\text { (caesarean/ } \\
\text { vaginal delivery) }\end{array}$ & $\begin{array}{l}95 \% \text { CI for } \\
\text { odds ratio }\end{array}$ \\
\hline \multicolumn{4}{|c|}{ Number of living children } \\
\hline 4 or more ${ }^{a}$ & $<0.001$ & 1 & \\
\hline 3 & $<0.001$ & 1.256 & $1.14-1.37$ \\
\hline 2 & $<0.001$ & 1.561 & $1.44-1.68$ \\
\hline 1 & $<0.001$ & 2.078 & $1.92-2.23$ \\
\hline 0 & $<0.001$ & 2.036 & $1.89-2.19$ \\
\hline \multicolumn{4}{|l|}{ Maternal age } \\
\hline Less than 19 years $^{\mathrm{a}}$ & $<0.001$ & 1 & \\
\hline 19-34 years & $<0.001$ & 1.531 & $1.43-1.63$ \\
\hline 35 years and over & $<0.001$ & 1.593 & $1.48-1.71$ \\
\hline \multicolumn{4}{|l|}{ Gestational age } \\
\hline 41 weeks and over ${ }^{a}$ & $<0.001$ & 1 & \\
\hline 37-40 weeks & $<0.001$ & 2.230 & $2.12-2.34$ \\
\hline 29-36 weeks & $<0.001$ & 2.941 & $2.74-3.14$ \\
\hline Less than 28 weeks & 0.002 & 1.222 & $1.07-1.38$ \\
\hline \multicolumn{4}{|l|}{ Number of abortions } \\
\hline $0^{\mathrm{a}}$ & $<0.001$ & 1 & \\
\hline 1 or 2 & $<0.001$ & 1.32 & $1.27-1.37$ \\
\hline 3 or more & $<0.001$ & 1.35 & $1.18-1.55$ \\
\hline \multicolumn{4}{|c|}{ Maternal underlying disease } \\
\hline $\mathrm{Yes}^{\mathrm{a}}$ & $<0.001$ & 1 & \\
\hline No & 0.005 & 1.13 & $1.04-1.24$ \\
\hline
\end{tabular}

a The reference point in this category upon which other subgroups are analysed.

to $131.3 \%$ from 2001 to 2007 [12] and Jordan, where it rose by $209 \%$ from 1990 to 2002 . The reasons for these increases are complex, and can be attributed to maternal requests, the reluctance of the providers to try a complicated normal vaginal delivery due to possible legal issues $[16,17]$, maternal underlying disease or foetal problems $[3,17,18]$.

The most prevalent yet preventable factor leading to the decision to use caesarean delivery was elective. Caesarean delivery was due to a variety of reasons such as maternal request [15] and the willingness of the providers to comply with the mother's request [10]. Since repeated caesarean delivery is associated with a higher risk of maternal and neonatal morbidity compared to repeated normal vaginal delivery [10], the increasing global trend towards caesarean delivery merits wider attention [10].

It is worth pointing out that another study [17] reported that elective caesarean delivery was the most prevalent reason for caesarean delivery. What we could not determine in the present study was whether the providers encouraged women to opt for caesarean delivery or wheth- er it was simply a matter of maternal choice. However, Janssens et al. [16] reported that pregnant women who had chosen private providers for delivery belonged to higher socioeconomic classes and were less likely to undergo an unwanted caesarean delivery. Furthermore, it has been reported that the increase in the rate of caesarean delivery was not only associated with problematic maternal or foetal conditions [14]. Therefore, interventions aimed at reducing the rate of caesarean delivery merit additional attention.

Of the total deliveries, $52.2 \%$ were performed by caesarean delivery, of which $37.7 \%$ were performed electively. On the other hand, $19.7 \%$ of all deliveries were performed by elective caesarean delivery. However, the actual rate of elective caesarean delivery can be assumed to be higher than the estimated $37.7 \%$. The reason for this may be related to legislation passed in 2006 indicating that 'no payment will be provided by insurance companies if the recorded reason for caesarean delivery is elective'. Hence, our data may have been biased by the fact that some private centres might have provided false reasons for choosing caesarean delivery instead of normal vaginal delivery.

As mentioned, the pregnant women who underwent caesarean delivery were significantly older than those with normal vaginal delivery, consistent with several other studies $[7,12,13,17,19,20,21]$. One of the reasons could be that mothers over the age of 34 were labelled as a high risk group for whom caesarean delivery was performed more frequently. However, our findings are incongruent with the results of a number of surveys conducted in settings where teenage pregnancies are common, particularly Sudan [11].

Most of our findings regarding the characteristics of women who underwent caesarean delivery are supported by other studies in which lower parity [17, 19-23], lower gestational age and a lower number of living children [17] were associated with caesarean delivery. However, none of these studies investigated the possible influence of previous abortions.

Several characteristics were predictors of caesarean delivery, such as increased maternal age, lower gravidity, gestational age, number of abortions, giving birth at a private hospital and maternal underlying disease. Some of these factors were also identified in other studies, e.g. maternal age [20-22], gravidity [22], gestational age [23], number of abortions [17], giving birth in a private hospital [17] and underlying disease [20,23]. In contrast to our findings, no correlation was found between maternal age and type of delivery in a study by Flores Padilla et al. [20] in 2008. We did not find any relationship between the 
number of living children and mode of delivery, in contrast to a study by Hsu et al. [23]. However, our analysis involved a census population-based dataset for 3 years, so our findings may be more conclusive compared to the data reported by Hsu et al. [23], which were based on a small fraction of deliveries in their centres.

Our study has several limitations, the most important of which is the use of previously recorded data. In addition, due to the large sample size, even slight changes in the rates of normal vaginal or caesarean delivery rates may result in statistically significant differences that lack clinical significance. However, the increasing trend towards caesarean delivery is not only statistically significant but also alarming.

The main strength of this study is that it included all recorded deliveries in Fars province for 3 consecutive years from the beginning of 2007 to the end of 2009. Therefore, we could reach a good estimation of caesarean and normal vaginal delivery rates in Fars, the fourth largest populated province in Iran. Our sample was also large enough to allow statistical comparisons between subgroups. Further- more, by using logistic regression to consider all factors together and decrease the effect of confounding factors, our study provides a solid evidence base for health policy makers who need to develop interventions that can influence demographic predictors of caesarean delivery.

\section{Conclusion}

This study found a high prevalence of caesarean delivery and an alarming upward trend in Fars province in the 3 years between January 2007 and January 2010. Therefore, particular attention should be directed towards mothers who are nulliparous or whose pregnancies are labelled high risk.

\section{Acknowledgments}

This study was supported by the Health Policy Research Centre. We would also like to express our special thanks to K. Shashok for her contribution to editing the manuscript.

\section{References}

1 Cuningham FG, Leveno KJ, Bloome SL, Hauth JC, Gilstrap LC, Wenstrom KD: Williams Obstetrics, ed 22. New York, McGrawHill, 2005, pp 865-866.

2 Lavender T, Hofmeyr GJ, Neilson JP, Kingdon C, Gyte GML: Caesarean section for non-medical reasons at term. Cochrane $\mathrm{Da}$ tabase Syst Rev 2006;3:CD004660.

-3 Ahmad-Nia S, Delavar B, Eini-Zinab H, Kazemipour S, Mehryar AH, Naghavi M: Caesarean section in the Islamic Republic of Iran: prevalence and some sociodemographic correlates. East Mediterr Health J 2009;15: 1389-1398.

4 The Fertility Health Assessment Program: Family health section. Tehran, Ministry of Health and Medical Education, 2005.

5 Phadungkiatwattana P, Tongsakul N: Analyzing the impact of private service on the cesarean section rate in public hospital Thailand. Arch Gynecol Obstet 2011;284:13751379.

6 Mendoza-Sassi RA, Cesar JA, Silva PR, Denardin G, Rodrigues MM: Risk factors for cesarean section by category of health service. Rev Saude Publica 2010;44:80-89.

7 Quiroz LH, Chang H, Blomquist JL, Okoh YK, Handa VH: Scheduled cesarean delivery: maternal and neonatal risks in primiparous women in a community hospital setting. Am J Perinatol 2009;26:271-277.
8 McCourt C, Weaver J, Statham H, Beake S, Gamble J, Creedy DK: Elective cesarean section and decision making: a critical review of literature. Birth 2007;34:65-79.

-9 World Health Organization: Appropriate technology for birth. Lancet 1985;2:436-437.

10 MacDorman MF, Menacker F, Declercq E: Cesarean birth in the United States: epidemiology, trends, and outcomes. Clin Perinatol 2008;35:293-307.

11 Khawaja M, Choueiry N, Jurdi R: Hospitalbased caesarean section in the Arab region: an overview. East Mediterr Health J 2009; 15 : 458-469.

12 Bogg L, Huang K, Long Q, Shen Y, Hemminki E: Dramatic increase of cesarean deliveries in the midst of health reforms in rural China. Soc Sci Med 2010;70:1544-1549.

13 Bovbjerg ML, Siega-Riz AM: Exercise during pregnancy and cesarean delivery: North Carolina PRAMS, 2004-2005. Birth 2009; 36:200-207.

14 Robson SJ, Tan WS, Adeyemi A, Dear KBG: Estimating the rate of cesarean section by maternal request: anonymous survey of obstetricians in Australia. Birth 2009;36:208212.

15 Ford J, Grewal J, Mikolajczyk R, Meikle S, Zhang J: Primary cesarean delivery among parous women in the United States, 19902003. Obstet Gynecol 2008;112:1235-1241.
16 Janssens S, Wallace KL, Chang AMZ: Prepartum and intrapartum caesarean section rates at Mater Mothers' Hospital Brisbane 1997-2005. Aust NZ J Obstet Gynaecol 2008; 48:564-569.

17 Khawaja M, Al-Nsour M: Trends in the prevalence and determinants of caesarean section delivery in Jordan: evidence from three demographic and health surveys, 1990-2002 (abstract). World Health Popul 2007;9:17-28.

18 Wilkes PT, Wolf DM, Kronbach DW, Kunze M, Gibbs RS: Risk factors for cesarean delivery at presentation of nulliparous patients in labor. Am J Obstet Gynecol 2003;102:13521357.

19 Hildingsson I: How much influence do women in Sweden have on caesarean section? A follow-up study of women's preferences in early pregnancy. Midwifery 2008;24:46-54.

-20 Flores Padilla L, González Pérez GJ, Trejo Franco J, Vega López G, Cabrera Pivaral CE, Campos A, Navarro Solares A, Navarro Núñez C: Risk factors in cesarean section (abstract). Ginecol Obstet Mex 2008;76:392-397.

21 Perveen S: Maternal and neonatal adverse outcome at repeat cesarean delivery versus repeat vaginal delivery. J Coll Physicians Surg Pak 2011;21:84-87.

22 Malloy MH: Impact of cesarean section on intermediate and late preterm births: United States, 2000-2003. Birth 2009;36:26-33.

23 Hsu KH, Liao PJ, Hwang CJ: Factors affecting Taiwanese women's choice of cesarean section. Soc Sci Med 2008;66:201-209. 